\title{
FLEISCHER, Soraya \& FERREIRA, Jaqueline (orgs.). 2014. Etnografias em serviços de saúde
}

Rio de Janeiro: Garamond. 360 pp.

\section{Rafaella Eloy de Novaes}

\section{(2) OpenEdition}

\section{Journals}

\section{Edição electrónica}

URL: http://journals.openedition.org/aa/2081

DOI: 10.4000/aa.2081

ISSN: 2357-738X

\section{Editora}

Programa de Pós-Graduação em Antropologia Social (UnB)

\section{Edição impressa}

Data de publição: 1 julho 2016

Paginação: 317-320

ISSN: 0102-4302

Refêrencia eletrónica

Rafaella Eloy de Novaes, «FLEISCHER, Soraya \& FERREIRA, Jaqueline (orgs.). 2014. Etnografias em serviços de saúde», Anuário Antropológico [Online], v.41 n. 1 | 2016, posto online no dia 05 junho 2018, consultado o 28 abril 2021. URL: http://journals.openedition.org/aa/2081 ; DOI: https://doi.org/ 10.4000/aa.2081

Este documento foi criado de forma automática no dia 28 abril 2021.

\section{(c) (1) (9)}

Anuário Antropológico is licensed under a Creative Commons Atribuição-Uso Não-Comercial-Proibição de realização de Obras Derivadas 4.0 International. 


\title{
FLEISCHER, Soraya \& FERREIRA, Jaqueline (orgs.). 2014. Etnografias em serviços de saúde
}

Rio de Janeiro: Garamond. 360 pp.

\author{
Rafaella Eloy de Novaes
}

\section{REFERÊNCIA}

FLEISCHER, Soraya \& FERREIRA, Jaqueline (orgs.). 2014. Etnografias em serviços de saúde. Rio de Janeiro: Garamond. 360 pp.

1 O instigante livro Etnografias em serviços de saúde, organizado pelas antropólogas Soraya Fleischer e Jaqueline Ferreira, reúne doze artigos que apresentam descrições densas do cotidiano de serviços de saúde vinculados ao sistema oficial de saúde brasileiro. Tratase de um livro em que o/a leitor/a pode visitar cenários, desde aqueles já consolidados em pesquisas em instituições de saúde pública, como ambulatórios, a outros inusitados, como o balcão de uma drogaria. A expressão "cenários" refere-se a espaços concretos, trazidos no livro, em que estão visíveis os sujeitos que neles circulam, as situações, os contextos e as próprias antropólogas - como as organizadoras do livro, opto por utilizar o termo "antropólogas" para me referir às autoras dos artigos, em sua maioria, mulheres. Nesses cenários, pode-se conhecer uma multiplicidade de discursos sobre cuidados e concepções de corpo, saúde, doença e cura; diálogos e ambiguidades entre profissionais de saúde, pacientes, famílias, gestores e comunidade; desenvolvimento local de políticas públicas de saúde, entre outros. É precisa, portanto, a presença da preposição de lugar "em" que, com as expressões "etnografias" e "serviços de saúde", confere título ao livro.

2 O "fio" que alinhava os cenários apresentados é, talvez, a desconstrução de uma suposta univocidade que parece nortear algumas noções presentes no Sistema Único de Saúde (SUS). Assim, ao considerar a dimensão da experiência que as pessoas normalmente 
chamadas de usuários/usuárias de serviços de saúde mental de algumas cidades de Santa Catarina possuíam em relação à reforma psiquiátrica, Ana Paula Müller de Andrade e Sônia Weidner Maluf optam por denominá-las de "experientes". Elas acompanham alguns experientes nos espaços institucionais por eles percorridos e em seus cotidianos. E, paulatinamente, o que é comumente tomado como reforma psiquiátrica configura-se como reformas psiquiátricas, em sua acepção plural.

3 Nessa direção, Mário Saretta questiona se, como antropólogos/as, seríamos capazes de ouvir as pessoas vinculadas a uma instituição psiquiátrica "dando- lhes, por princípio, a mesma atenção que costumamos dar aos médicos” (:59). É o que ele faz em uma etnografia com participantes de uma Oficina de Criatividade em um Hospital Psiquiátrico. Sem desqualificar o conhecimento psicológico, neurológico e/ou psiquiátrico a respeito da loucura, Saretta aproxima-se da comumente considerada escuridão da loucura, em oposição a uma suposta claridade da razão, na tentativa de possibilitar que algumas luzes, não perceptíveis numa visão demasiada racional, sejam vistas (:78). Com Marcos Carvalho, por sua vez, ouvimos as vozes de uma equipe de saúde e de usuários de um Centro de Atenção Psicossocial localizado em uma cidade média do interior paulista. $\mathrm{O}$ autor apresenta algumas reuniões com usuários e a equipe dessa unidade de saúde, bem como o processo de implantação de uma proposta do SUS denominada Conselho Gestor.

4 Não estão visíveis no livro apenas as antropólogas e os outros sujeitos que circulam nos cenários etnografados, mas sobretudo as próprias relações entre eles. Nessesentido, Jaqueline Ferreiraapresentadadosdeseutrabalhodecamporealizado durante dois anos em um centro de saúde do Médecins du Monde (MDM), uma espécie de estrutura humanitária em Paris. A intenção da "antropóloga médica", como Ferreira refere-se a si mesma (:135), era observar a relação entre os médicos voluntários do MDM e a população que eles atendiam no espaço da consulta médica - estrangeiros vivendo em situação de clandestinidade, imigrantes sans papiers (africanos originários de Mali, Costa do Marfim, Congo, Senegal), franceses moradores de rua e indivíduos em fase final do auxílio-desemprego.

5 Numa perspectiva semelhante, Sabrina Pereira Paiva e Elaine Reis Brandão captam as relações entre os balconistas de uma drogaria da zona norte do município do Rio de Janeiro, o levonorgestrel (CE), popularmente conhecido como pílula do dia seguinte, e os/as consumidores/as. As autoras nos apresentam um campo permeado de hierarquias, noções de pessoa, gênero e sexualidade, bem como aspectos das divisões simbólicas do espaço da cidade que, na visão dos balconistas, pareciam interferir na venda e no consumo do CE. Pedro Nascimento e Ariana Cavalcante de Melo, por sua vez, descrevem os saberes e posicionamentos de mulheres sobre cuidados reprodutivos, no que tange à concepção e contracepção, bem como a relação entre os profissionais de saúde de duas unidades de saúde em Maceió e as mulheres nelas atendidas.

6 Com o "antropólogo paciente" (talvez pudéssemos chamar Rodrigo Toniol assim!), a noção de integralidade que sustenta a Política Nacional de Práticas Integrativas e Complementares (PNPIC) é problematizada. Engajado no trabalho de campo constituído de consultas (cujo paciente era ele mesmo) em um ambulatório vinculado ao SUS, numa região bastante empobrecida da cidade de Porto Alegre, que atende exclusivamente com terapêuticas integrativas e complementares, o autor descreve o processo de elaboração e implantação da PNPIC, oficializada no Brasil em 2006, cuja finalidade é assegurar e promover o acesso, no SUS, à medicina tradicional chinesa, à homeopatia, à 
fitoterapia, ao termalismo e à medicina antroposófica. Para Toniol, se a integralidade é um argumento garantidor de que a PNPIC está alinhada com os princípios doutrinários do SUS, há diferenças nos sentidos atribuídos a ela no âmbito da PNPIC e do SUS.

Com Soraya Fleischer e Monique Batista somos conduzidos à área externa de um centro de saúde na Guariroba, Ceilândia, região administrativa do Distrito Federal, onde encontramos pessoas participando de um grupo de ginástica. Com elas, é possível pensar a polissemia que envolve os termos "serviços", "saúde", "cuidados", "doença" e "cronicidade". Nessa mesma direção, Rosamaria Carneiro realiza uma etnografia de dois grupos de preparo para o parto, constituídos por adeptas do parto humanizado. A univocidade que parece reger as expressões "mais natural", "natural" e "humanizado", normalmente utilizadas em oposição ao parto cesáreo, perde sua veracidade à medida que a antropóloga problematiza as acepções que envolvem a noção de parto humanizado, desalojando aproximações com uma suposta fixidez do par natureza/ cultura. Rosana Castro também desconstrói algumas noções aparentemente unívocas, tais como eficácia, segurança, benefícios, medicamentos e riscos, à medida que descreve os debates e as controvérsias ocorridos na Agência Nacional de Vigilância Sanitária em torno da regulamentação do consumo de quatro substâncias controladas, oficialmente indicadas para perda de peso - anfepramona, femproporex, mazindol e sibutramina.

8 Em etnografia realizada em um Comitê de Ética em Pesquisa (CEP), Rui Harayama problematiza a noção de riscos, à medida que apresenta os sentidos dados pelos membros do CEP ao que seria uma pesquisa ética. Priscila Farfan Barroso, Daniela Riva Knauth e Paula Sandrine Machado descrevem os sentidos que dois modelos de atenção, representados por dois serviços de saúde localizados em um município do Rio Grande do Sul, conferem aos processos de desintoxicação, à prescrição de medicamentos e à reinserção social. o primeiro modelo é voltado ao atendimento do usuário de drogas no âmbito do hospital; o outro, denominado psicossocial, centra-se no acolhimento ambulatorial do usuário de drogas.

Não me surpreenderá que o/a leitor/a de Etnografias em serviços de saúde se perceba caminhando pelos corredores da instituição pública onde se reúne o CEP pesquisado por Harayama, na tentativa de, quem sabe, deparar-se com um dos seus membros e dialogar com ele/a sobre as dificuldades vivenciadas por pesquisadores/ as das ciências sociais e humanas para atender aos procedimentos éticos normativos para realização de pesquisas com seres humanos em instituições oficiais de saúde brasileiras; ou, ainda, dialogando com um dos entregadores de fármacos que fica sentado no passeio, do lado de fora da drogaria, enquanto aguarda os pedidos de entrega. Tampouco me surpreenderá que, nos cenários apresentados no livro, o/a leitor/a encontre elementos de diálogo com os cenários por ele/a percorridos em seu cotidiano, seja como pesquisador/a, usuário/a (experiente?) ou trabalhador/a de serviços de saúde.

A polissemia presente no funcionamento de serviços de saúde vinculados ao sistema oficial de saúde brasileiro constitui uma grande riqueza para o olhar antropológico. 0 livro mostra que torná-la visível pode ser uma grande contribuição para o SUS. Longe de argumentar que o livro traga modelos para a condução de etnografias em serviços de saúde, Fleischer e Ferreira apontam que tais etnografias estão em constante construção. Elas sugerem que, ao realizá-las, torna-se necessário "aceitar o seu caráter inesperado, para que seus riscos e desafios possam sempre nos surpreender" (:13). Etnografias em serviços de saúde não se configura como modelo, tampouco cartilha; é, 
sobretudo, um convite inspirador para alargar os cenários nele reunidos e nos deixar mover por esse tal inesperado que envolve qualquer etnografia.

\section{AUTORES}

\section{RAFAELLA ELOY DE NOVAES}

UFG 